Int. J. Morphol.,

35(2):425-429, 2017

\title{
Multiple Software Based 3D Modeling Protocol for Printing Anatomical Structures
}

\author{
Protocolo de Impresión 3D de Estructuras Anatómicas \\ Basados en la Utilización de Software Múltiple
}

Coronel Javier ${ }^{1}$; Palacio Juliana ${ }^{2}$ \& Rueda-Esteban Roberto ${ }^{3}$

CORONEL, J.; PALACIO, J. \& RUEDA-ESTEBAN, R. Multiple software based 3D modeling protoco for printing anatomical structures . Int. J. Morphol., 35(2): 425-429, 2017.

SUMMARY: With the increasing number of medical programs, research for new teaching methods has also emerged. Computer software and diagnostic images have been used for anatomy teaching as an alternative to cadaver dissection, which means students cannot develop a mental image of the human body without compromising spatial reasoning. Also the cadavers present flaws such as color, texture and smell. This paper explains in details the protocol used to reconstruct 3D models for rapid prototyping as an overcome to these difficulties. Online Computerized Tomography scans were obtained in DICOM format from OsiriX and InVesalius. Reconstruction of 3D models from aortic and superior tracheobronchial tract structures were created, InVesalius and Rhinoceros software were used. 3D models of a heart with its aorta, superior tracheobronchial tract and an aneurysm at the aortic bifurcation were obtained for rapid prototyping. The superior tracheobronchial tract model was printed. It is possible to produce printed models from CT scans using different softwares for 3D modeling and rapid prototyping. These models could allow the student to develop a three dimensional mental image of the human body according to literature.

KEY WORDS: 3D Printing; Anatomical Models; Educational Technologies; Computing Methodology.

\section{INTRODUCTION}

With the increasing number of medical programs, the research of new ways of teaching has also arisen, especially in anatomy as one of the major basics subjects in medicine (Korf et al., 2008). The impact of anatomical education improvement is critical since the students learn a basic knowledge that will be applied into their clinical workplace. Cadaver dissection has been used since 1800 for anatomy classes (Korf et al.), but the difficulty to obtain human bodies for educational purposes is increasing (Aversi-Ferreira et al., 2010; Vera; Lucchese, 2010) also the use of fixated cadavers have disadvantages such as their color, texture and smell (McLachlan, 2004). Finally the use of corpses for classes is costly and labour intensive. Equally for a dissection to be effective, skills are needed and the corpses do not last long (Rizzolo \& Stewart, 2006). Because of these limitations, computer programs, websites, computer software and diagnostic images are being used to teach anatomy (Korf $e t$ $a l$.). The main problem with these technologies lies in the students' inability to generate functional three dimensional images, compromising spatial reasoning (Rizzolo \& Stewart). At the university anatomy laboratory, the use of 3D models have been proposed for anatomy teaching to overcome such difficulties. The use of printed 3D models implies rapid prototyping, which focus on industrial prototyping for medical applications (Huotilainen et al. n.d.).

The theory for 3D printing was created by professor Herbert Voelcker in 1960 but the technology to print appeared only in 1987 thanks to Carl Deckard (Bagaria et al., 2011). $3 \mathrm{D}$ printing is based in the construction layer by layer of a physical structure that represents a virtual model (Li et al., 2015). This process has demonstrated to be cost-effective and highly accurate (Bagaria et al.), since the structure comes from a virtual model, $3 \mathrm{D}$ printing allows to make almost

\footnotetext{
${ }^{1}$ Anatomy for Education Research Group, Universidad de los Andes, Faculty of Engineering, Biomedical Engineer, Bogotá D.C., Colombia.

${ }^{2}$ Anatomy for Education Research Group, Universidad de los Andes, School of Medicine student, Bogotá D.C., Colombia.

${ }^{3}$ M.D. M. Ed.Anatomy for Education Research Group, Universidad de los Andes School of Medicine Assistant Professor, Anatomy, Laboratory Coordinator, Bogotá D.C., Colombia.
} 
any kind of structure. Meaning not only a representation of any healthy organ can be obtained but also pathogenic ones, which are rare to acquire from a corpse. This paper explains in detail a protocol used at our anatomy laboratory for 3D reconstruction of several image models, three of them corresponding to the aortic arch and heart, trachea and iliac arteries and the printing of a model of superior tracheobronchial tract shown as results.

\section{MATERIAL AND METHOD}

Data acquisition. To obtain the necessary files for reconstruction, online databases were used. OsiriX is an open-source software for MacOS that allows the management and interpretation of large sets of medical images such as Computerized Tomography scans (CT) (Rosset et al., 2004). This software also provides a free dataset of medical images posted in their web site. The datasets are composed of medical imaging sequences in DICOM format (Digital Imaging and Communication in Medicine) obtained from a CT scans and has no labels about patient information. Two samples of OsiriX database were downloaded to process their files and create a $3 \mathrm{D}$ model, the name and the characteristics of the downloaded samples were the following: 1. Artifix: CT scan of dilated aorta. 2. Macoessix: CTA scan of lower limbs.

A second database was used, InVesalius reconstruction software (CTI Renato Archer, São Paulo, Brazil) also provides free CT samples on its website. The name and the characteristics of the downloaded samples were the following: 3. Thorax-Abdo: CTA scan of chest.

Data processing and segmentation. Once downloaded the DICOM files, the software InVesalius was selected for the management and visualization of these DICOM collections. InVesalius is a free medical software developed in Brazil, chosen because of its different functionalities and 3D medical imaging solutions such as: segmentation tools, 3D reconstruction and 3D model generation for Rapid Prototyping (Martins et al., 2008).

The OSIRIX datasets were imported to InVesalius to select the structures related to the aortic arteries. As the gray level of the pixels in DICOM files is determined by the density of the tissue, the segmentation was implemented by thresholding. This technique allows to establish a range of gray levels in the image and select the desired ones (Jacobs et al., 2008; Li et al.). According to this, to select aortic arteries, the designated threshold doesn't include gray levels corresponding to bones, epithelial tissue or fat tissue. The threshold tool of the software also allows to manually erase or include using a paintbrush.

The first approach for the segmentation of trachea was as in the other dataset, importing the full DICOM volume to the software and implement a threshold to select desired structures. After this, the 3D surface was generated, but the level of detail in the trachea was not the desired. Because of this, it was decided to implement an algorithm with Matlab for this specific model. In a first stage, the full DICOM volume was imported to Matlab, then, slice by slice of the volume was examined to establish the regions which corresponded to the trachea. Finally, the DICOM volume was cropped and instead of having a DICOM volume of the whole body, the final volume only contained the respiratory tract region. To select respiratory tract, the threshold was specific with a gray level range corresponding to lung tissue. After segmentation, a 3D surface was created with InVesalius.

It is important to stand out that, to obtain each final model, it was necessary to manually erase other organs that were included using the threshold.

Final 3D model. InVesalius allows to export the 3D surface in different formats. Generally, the desired format for rapid prototyping is a stereolithography file (STL) (Li et al. 2015), so each surface was exported as an STL. This STL contains a surface composed of triangles and squares arrangements, these polygons are in charge of shaping the surface (Fig. 1). Surface modeling for each model was completed by manipulating the STL in the modeling software Rhinoceros 5.0 (McNeel Europe, Spain) where extra vessels and structures were removed and the openings in the surface were covered with meshes to prevent errors in the triangulated surface (Sun et al., 2004). The models also were scaled to real dimensions in Rhinoceros, the STL format remained. The complete process of reconstruction and modeling is resumed in figure 2 shows a comparison between the STL file and the final 3D printed model (Figs. 1 and 2).

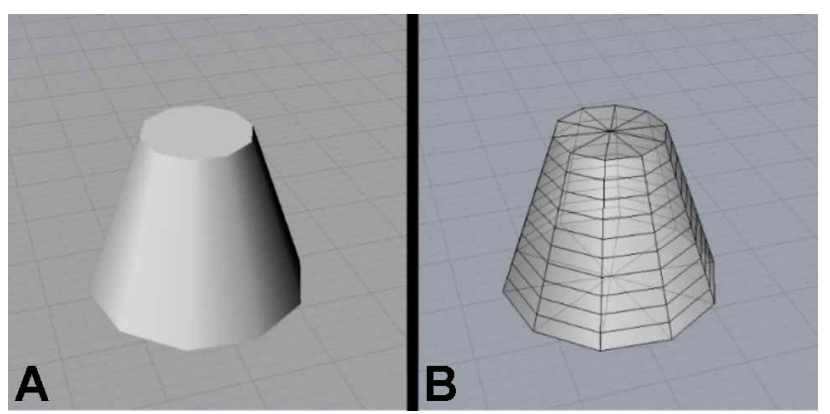

Fig. 1. A. Surface representation; B. Mesh representation. 


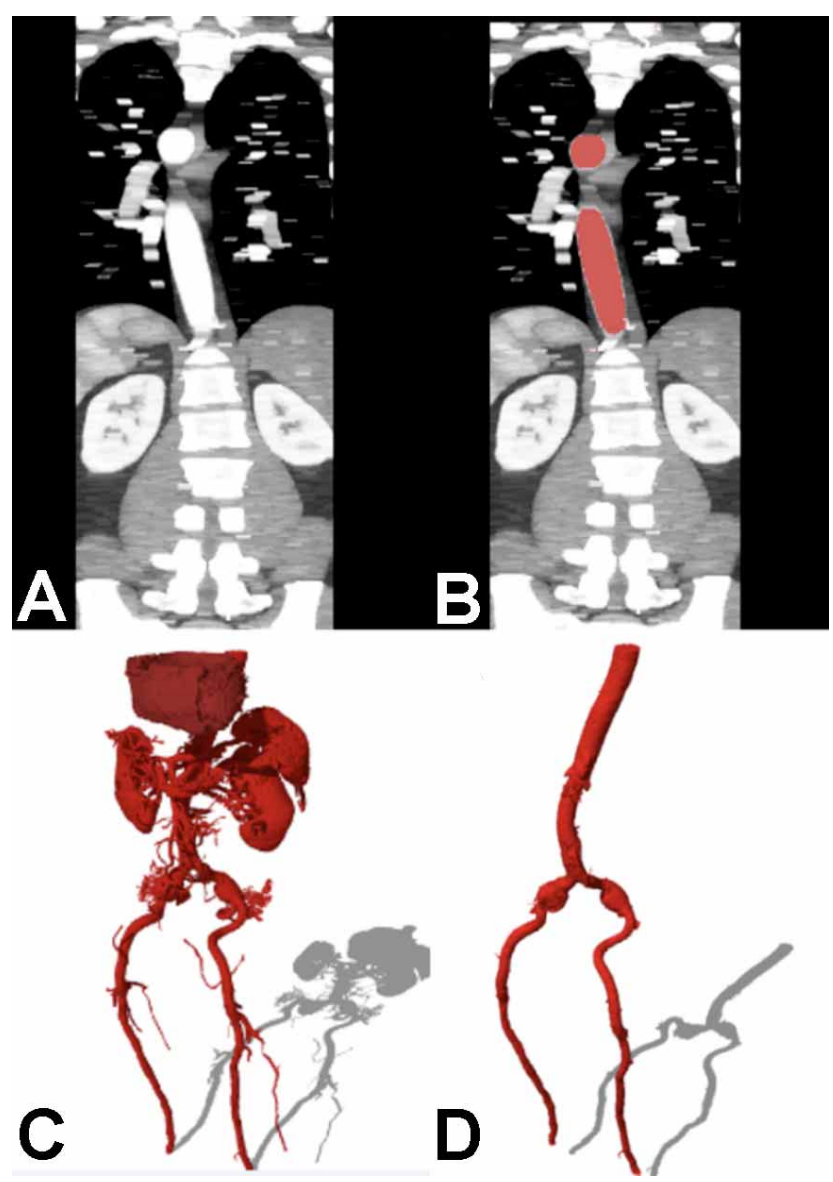

Fig. 2. Process to get a final model. A. DICOM files; B. Segmentation (InVesalius) C. 3D Reconstruction (InVesalius) D. 3D Modeling (Rhinoceros).

\section{RESULTS}

For Artifix dataset (Fig. 3), the final model is composed of heart, aortic and pulmonary arteries. Its final dimensions are $29.767 \mathrm{~cm}$ height, $14.896 \mathrm{~cm}$ width and $11.900 \mathrm{~cm}$ depth. It is composed of a mesh with 631382 polygons. The number of polygons define the quality of each structure. The more polygons, better defined are the curved parts of the structure (Fig. 3).

The first model for Macoessix obtained from InVesalius (Fig. 4A), had structures corresponding to kidneys and spleen irrigation. After the manipulation of the model in Rhinoceros, the final 3D model (Fig. 4B) contains only abdominal and iliac arteries. On the final model, some aneurysms at the aortic bifurcation can be identified. Its final dimensions $61.768 \mathrm{~cm}$ height, 15.837 $\mathrm{cm}$ width and $9.306 \mathrm{~cm}$ depth. The mesh is composed of 85644 polygons (Fig. 4).

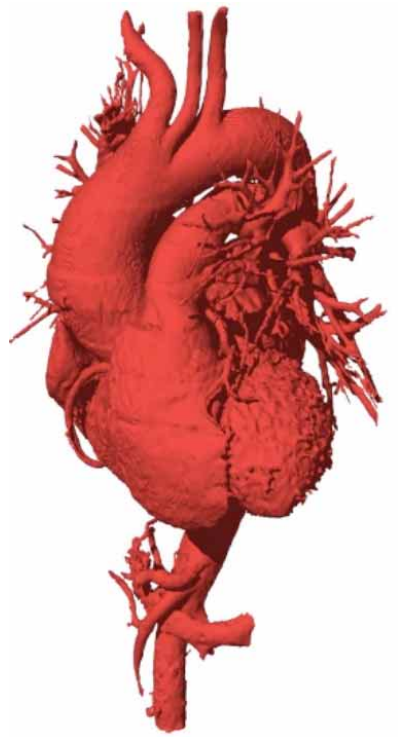

Fig. 3. Artifix final model.

A
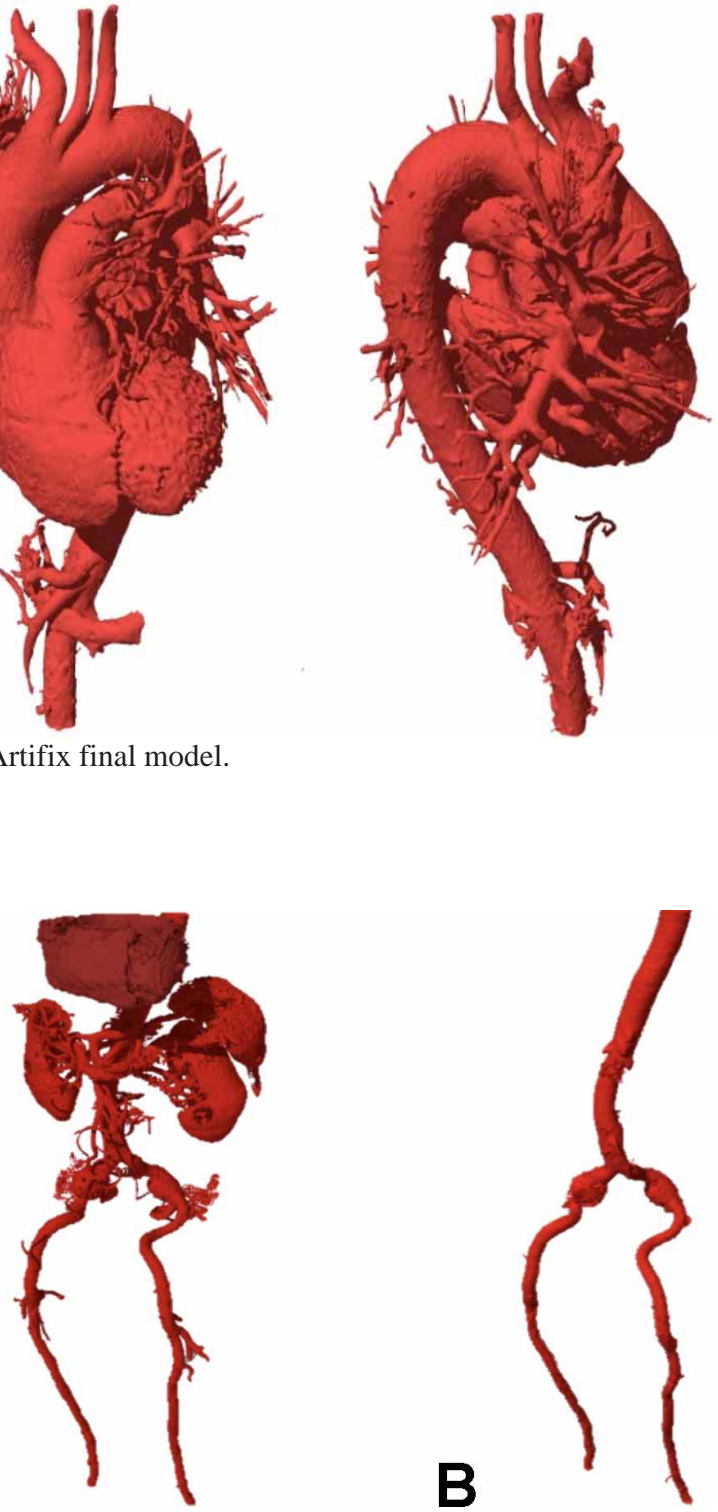

Fig. 4. Macoessix models. A. Original model form InVesalius; B. Final model.

The first model of superior tracheobronchial tract (STBT) which refers to the respiratory tract under the larynx contained also visceral pleura, part of lung parenchyma, bronchi and bronchioles (Fig. 5A), but after using Rhinoceros on the model, it was only composed by the STBT, primary bronchi, and part of secondary bronchi (Fig. 5B). Its final dimensions $16.226 \mathrm{~cm}$ height, $9.673 \mathrm{~cm}$ width and 3.032 $\mathrm{cm}$ depth. The mesh is composed of 8421 polygons. Finally, the data was sent as STL file for its 3D printing, achieving a final model (Figs. 6A-6C). finally figure 7 shows a comparison between the STL file and the final 3D printed model. (Figs. 5, 6 and 7). 


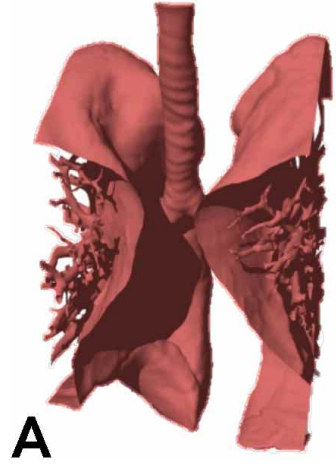

B

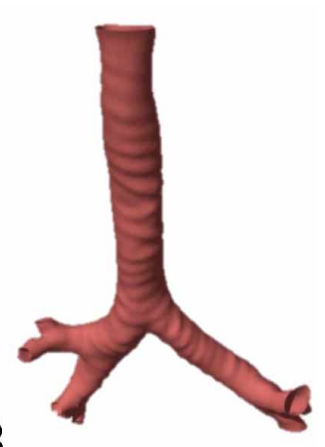

Fig. 5. STBT models. A. Original model form InVesalius; B. Final model.

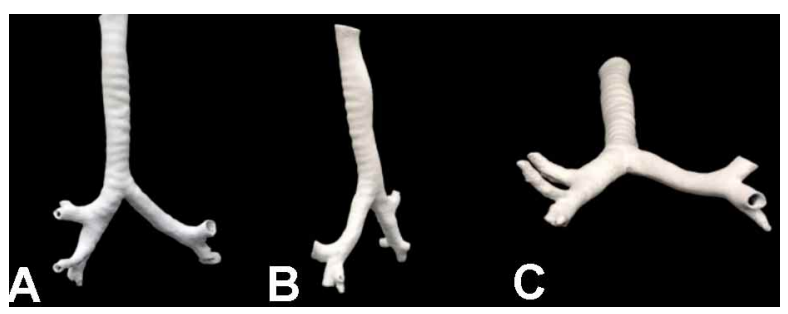

Fig. 6. 3D printed models. A. Frontal view; B. Lateral view; C. Oblique view.

A

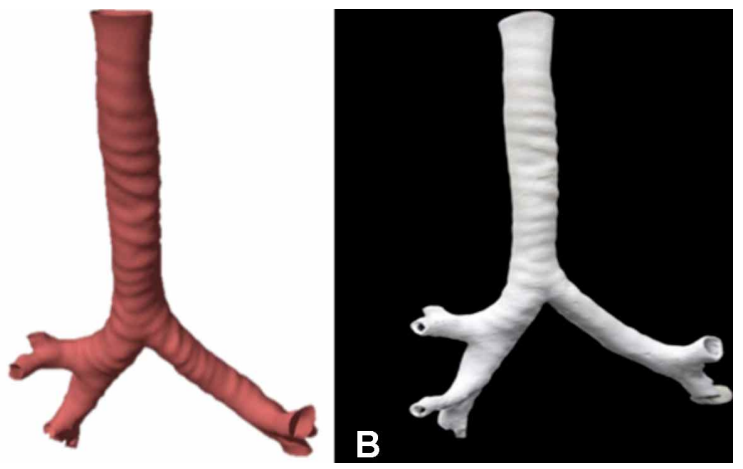

Fig. 7. Comparison between the STL file and the final 3D printed model. A. STL file; B. 3D printed model.

\section{DISCUSSION}

The obtained models have long shelf life and can be painted in a way which resembles the real human body thanks to the material used.

Despite segmentation process with InVesalius is very useful to delete unnecessary structures; the first 3D models obtained with the reconstruction weren't entirely clean. These models include structures related with the main organ. In the STBT model, the visceral pleura and pulmonary parenchyma were present, but these are not significant for the model (Fig. 5). Example of this is the kidney irrigation in Macoessix model, or the lobes and bronchioles in tracheal model. One way to improve this result is, as shown above, using a 3D modeling software with which those secondary structures can be erased and also the 3D model improved to obtain a uniform and soft surface. Other way to solve this problem is by doing the reconstruction with DICOM images previously segmented using algorithms and methods of biomedical computer vision. Previous work has shown an algorithm segmentation of tubular structures of determined size, using this algorithm a segmentation of coronary arteries was done successfully (Yang et al., 2013). Similar work could be applied for the segmentation of abdominal aorta for example.

The number of polygons is slightly independent on the model's size, despite Macoessix model is the largest, its number of polygons is not even half of the number of polygons in Artifix model. This because Artifix model has more number of details and small structures that need to be represented by a larger number of polygons.

As the final models are in STL format, they are ready for impression using a rapid prototyping machine (Greil et al., 2007; Jacobs et al.).

In the search for new methods used as an alternative to dissection they should proceed according to the principles of motivation: curiosity, relevance, success, extrinsic and intrinsic motivators, and self-regulation strategies when obstacles come in the way of studying. If the students are not motivated they will not persist with their learning process (Eagleton, 2015). Also the cognitive theory should be considered if the educator is aiming for a permanent repository of knowledge such as long-term memory. This theory, refers the study of the mental mechanisms of learning, considering the influence of the learner in learning. For that type of memory to appear, sensory memory and working memory should be activated (Terrell, 2006). Rapid prototyping appeared as a technology for producing physical models in a fast way from digital data (Mcmenamin et al., 2014). Based on this theory and according to literature, these printed models will allow students to interact with real life representations of what is described in their Anatomy textbooks, resulting in a better understanding of studied structures. Also, if the students are involved in the design of the model, principles of motivation are met, activating the sensory and working memory (Terrell).

The future use of these methods to improve teaching is essential, it is known that the future performance of the students in the clinical flied depends strongly in the knowledge of anatomy (Boon et al., 2001). While the students use the printed models, they will be able to compare them with the textbooks so that in the future they can make a good interpretation of an anatomical image with the comprehension of three-dimensional relationships of the human body leading them to success in clinical procedures (Terrell). These correlation with the future medical practice is what stimulates most of the students (Boon et al.). 
As the printed models will be used in a community and not by just one single student, the interaction within groups associated with learning tools impacts in a very meaningful way the acquisition of knowledge (Burgess \& RamseyStewart, 2015).

Summarizing, the use of rapid prototyping techniques can allow the development of a three dimensional mental image of the human body improving the understanding of anatomy that will be essential in the clinical field.

In conclusion, the value of this work is the reconstruction of anatomical structures using different software, this reconstruction could be done in an academic environment and no specialized knowledge of radiology, medical image analysis or 3D modeling is required.

CORONEL, J.; PALACIO, J. \& RUEDA-ESTEBAN, R. Protocolo de impresión 3D de estructuras anatómicas basados en la utilización de software múltiple. Int. J. Morphol., 35(2) :425-429, 2017.

RESUMEN: Con el incremento en el número de programas médicos, la búsqueda por nuevos métodos de enseñanza también ha emergido. Software computarizado e imágenes diagnósticas han sido utilizados en la enseñanza de anatomía como una alternativa a la disección cadavérica, lo que conlleva a que los estudiantes no puedan desarrollar una imagen mental del cuerpo humano sin comprometer el raciocinio espacial. También los cadáveres presentan desventajas como color, textura y olor. Este artículo explica en detalle el protocolo usado para la reconstrucción de modelos 3D para prototipado rápido como un recurso para superar estas dificultades. Tomografías computarizadas online fueron obtenidas en formato DICOM de OsiriX e InVesalius. La reconstrucción en 3D de modelos de estructuras aórticas y del ducto traqueobronquial fueron creadas con los software InVesalius y Rhinoceros. Modelos 3D de corazón y aorta, el ducto traqueobronquial y un aneurisma aórtico abdominal en su bifurcación fueron obtenidos para la prototipado rápido. El modelo de ducto traqueobronquial fue impreso. Es posible producir modelos de TC usando diferentes programas de modelado 3D. Estos modelos podrían permitir a los estudiantes desarrollar una imagen metal tridimensional del cuerpo humano según la literatura.

\section{PALABRAS CLAVE: Impresión 3D; Modelos Anatómicos; Tecnologías de educación; Metodología computacional.}

\section{REFERENCES}

Aversi-Ferreira, T. A.; Nascimento, G. N. L.; Vera, I. \& Lucchese, R. The practice of dissection as teaching methodology in anatomy applied to medical education. Int. J. Morphol., 28(1):265-72, 2010.

Bagaria, V.; Rasalkar, D.; Bagaria, S. J. \& Ilyas, J. Medical Applications of Rapid Prototyping - A New Horizon. In: Hoque, M. E. (Ed.). Advanced Applications of Rapid Prototyping Technology in Modern Engineering. Intech, 2011. pp.1-20. Available from: http://www.intechopen.com/ books/advanced-applications-of-rapid-prototyping-technology-inmodern-engineering/medical-applications-of-rapid-prototyping-a-newhorizon

Boon, J. M.; Meiring, J. H.; Richards, P. A. \& Jacobs, C. J. Evaluation of clinical relevance of problem-oriented teaching in undergraduate anatomy at the University of Pretoria. Surg. Radiol. Anat., 23(1):57-60, 2001.

Burgess, A. \& Ramsey-Stewart, G. Anatomy by whole body dissection: a focus group study of students' learning experience. Adv. Med. Educ. Pract., 6:533-7, 2015.

Eagleton, S. An exploration of the factors that contribute to learning satisfaction of first-year anatomy and physiology students. Adv. Physiol. Educ., 39(3):158-66, 2015.

Jacobs, S.; Grunert, R.; Mohr, F. W. \& Falk, V. 3D-Imaging of cardiac structures using 3D heart models for planning in heart surgery: a preliminary study. Interact. Cardiovasc. Thorac. Surg., 7(1):6-9, 2008.

Korf, H. W.; Wicht, H.; Snipes, R. L.; Timmermans, J. P.; Paulsen, F.; Rune, G. \& Baumgart-Vogt, E. The dissection course - necessary and indispensable for teaching anatomy to medical students. Ann. Anat., 190(1):16-22, 2008.

Li, Z.; Li, Z.; Xu, R.; Li, M.; Li, J.; Liu, Y.; Sui, D.; Zhang, W. \& Chen, Z. Three-dimensional printing models improve understanding of spinal fracture--A randomized controlled study in China. Sci. Rep., 5:11570, 2015.

Martins, T. A. C. P.; Santa Bárbara, A.; Silva, G. B.; Faria, T. V.; Cassaro, B. \& Silva, J. V. L. InVesalius: Three-dimensional Medical Recontruction Software. In: Bartolo, P. J. (Ed.). Virtual and Rapid Manufacturing. Advanced Research in Virtual and Rapid Prototyping.
London, Taylor \& Francis Group, 2008. pp.135-47.

McLachlan, J. C. New path for teaching anatomy: living anatomy and medical imaging vs. dissection. Anat. Rec. B New Anat., 281(1):4-5, 2004

McMenamin, P. G.; Quayle, M. R.; McHenry, C. R. \& Adams, J. W. The production of anatomical teaching resources using three-dimensional (3D) printing technology. Anat. Sci. Educ., 7(6):479-86, 2014.

Rizzolo, L. J. \& Stewart, W. B. Should we continue teaching anatomy by dissection when ...? Anat. Rec. B New Anat., 289(6):215-8, 2006.

Rosset, A.; Spadola, L. \& Ratib, O. OsiriX: An open-source software for navigating in multidimensional DICOM images. J. Digit. Imaging, 17(3):205-16, 2004

Sun, W.; Starly, B.; Darling, A. \& Gomez, C. Computer-aided tissue engineering: application to biomimetic modelling and design of tissue scaffolds. Biotechnol. Appl. Biochem., 39(Pt. 1):49-58, 2004.

Terrell, M. Anatomy of learning: instructional design principles for the anatomical sciences. Anat. Rec. B New Anat., 289(6):252-60, 2006.

Greil, G. F.; Wolf, I.; Kuettner, A.; Fenchel, M.; Miller, S.; Martirosian, P.; Schick, F.; Oppitz, M.; Meinzer, H. P. \& Sieverding, L. Stereolithographic reproduction of complex cardiac morphology based on high spatial resolution imaging. Clin. Res. Cardiol., 96(3):176-85, 2007.

Yang, F.; Hou, Z. G.; Mi, S. H.; Bian, G. B. \& Xie, X. L. 3D Modeling of Coronary Arteries Based on Tubular-Enhanced CURVES Segmented Regions for Robotic Surgical Simulation. Shenzhen, 2013 IEEE International Conference on Robotics and Biomimetics (ROBIO), 2013. pp.2013-18.

Corresponding author:

Juliana Palacio Varona

Received: 31-08-2016

Universidad de los Andes

Accepted: 20-01-2017

Grupo de Instigación en Anatomía para la Educación

Bogotá - COLOMBIA

E-mail: j.palacio837@uniandes.edu.co 